\title{
Low competitive status elicits aggression in healthy young men: behavioural and neural evidence
}

\author{
Macià Buades-Rotger, (ib 1,2,3 Martin Göttlich, ${ }^{1}$ Ronja Weiblen, ${ }^{1,4}$ \\ Pauline Petereit, ${ }^{1}$ Thomas Scheidt, ${ }^{1}$ Brian G. Keevil, ${ }^{5}$ and \\ Ulrike M. Krämer ${ }^{1,2,6}$
}

${ }^{1}$ Department of Neurology, University of Lübeck, Lübeck, Schleswig-Holstein 23562, Germany, ${ }^{2}$ Department of Psychology, University of Lübeck, Lübeck, Schleswig-Holstein 23562, Germany, ${ }^{3}$ Donders Institute for Brain, Cognition and Behaviour, Radboud University, Nijmegen, Gelderland 6525 HR, The Netherlands, ${ }^{4}$ Department of Psychiatry and Psychotherapy, University of Lübeck, Lübeck, Schleswig-Holstein 23562, Germany, ${ }^{5}$ Department of Clinical Biochemistry, University Hospital of South Manchester, Manchester, M23 9LT, UK, and ${ }^{6}$ Center of Brain, Behavior and Metabolism (CBBM), University of Lübeck, Lübeck, Schleswig-Holstein 23562, Germany

Correspondence should be addressed to Macià Buades-Rotger, Donders Institute for Brain, Cognition and Behaviour, Radboud University, Montessorilaan 3, Nijmegen, Gelderland 6525 HR, The Netherlands. E-mail: m.buadesrotger@donders.ru.nl.

\begin{abstract}
Winners are commonly assumed to compete more aggressively than losers. Here, we find overwhelming evidence for the opposite. We first demonstrate that low-ranking teams commit more fouls than they receive in top-tier soccer, ice hockey and basketball men's leagues. We replicate this effect in the laboratory, showing that male participants deliver louder sound blasts to a rival when placed in a low-status position. Using neuroimaging, we characterize brain activity patterns that encode competitive status as well as those that facilitate status-dependent aggression in healthy young men. These analyses reveal three key findings. First, anterior hippocampus and striatum contain multivariate representations of competitive status. Second, interindividual differences in status-dependent aggression are linked with a sharper status differentiation in the striatum and with greater reactivity to status-enhancing victories in the dorsal anterior cingulate cortex. Third, activity in ventromedial, ventrolateral and dorsolateral prefrontal cortex is associated with trial-wise increases in status-dependent aggressive behaviour. Taken together, our results run counter to narratives glorifying aggression in competitive situations. Rather, we show that those in the lower ranks of skill-based hierarchies are more likely to behave aggressively and identify the potential neural basis of this phenomenon.
\end{abstract}

Key words: aggression; status; competition; fMRI; neuroimaging

\section{Introduction}

Winners are often taken to be aggressive, not only in sportive environments (Chow et al., 2009; Trebicky et al., 2013) but in society at large (Waasdorp et al., 2013; Laustsen and Petersen,
2017; Cheng, 2020; Weick, 2020). Indeed, adjectives such as 'aggressive' or 'dominant' are frequently casted in a positive light in competitive contexts (Næss, 2001; Pappas et al., 2004), and leaders perceived to possess these characteristics are pre-

Received: 26 August 2020; Revised: 23 April 2021; Accepted: 5 May 2021

(C) The Author(s) 2021. Published by Oxford University Press.

This is an Open Access article distributed under the terms of the Creative Commons Attribution-NonCommercial License (http://creativecommons.org/ licenses/by-nc/4.0/), which permits non-commercial re-use, distribution, and reproduction in any medium, provided the original work is properly cited. For commercial re-use, please contact journals.permissions@oup.com 
ferred in conflict situations (Kakkar and Sivanathan, 2017). From this perspective, aggression might serve to both achieve and assert a higher social rank (Lee and Yeager, 2020). In agreement with this idea, individualstend to deliver louder sound blasts to a rival they outperformed than to one who outperformed them (Muller et al., 2012). Contradicting these findings, the lower sense of control and the frustration occasioned by frequent defeats can fuel aggression in subordinate competitors (Przybylski et al., 2014; Oxford et al., 2017; Dowsett and Jackson, 2019). Supporting this notion, a number of studies have shown that individuals are more aggressive towards persons with high status (Davis and Reyna, 2015; Hu et al., 2016; Saalfeld et al., 2018; Kakkar et al., 2019), as low status might impede goal attainment (Berkowitz, 2012), induce stress (Sapolsky, 2004, 2005) and threaten self-image (Horton and Sedikides, 2009). Furthermore, while accomplished contestants can rely on their ability, less proficient ones might compete more aggressively to outweigh the skill differential (Kirker et al., 2000; Coulomb-Cabagno and Rascle, 2006). Hence, those in the lower ranks of skill-based hierarchies might be more prone to use aggression than those who win consistently. If that were the case, social narratives emphasizing aggressiveness as a requisite for competitive success would be misguided. Here, we tested whether competitive status is related to physical aggression and investigated the neural underpinnings of this association.

Status-based hierarchies order social life and are hence imprinted in human neurobiology (Qu et al., 2017). The rostral aspect of the medial prefrontal cortex (mPFC) has been postulated as a crucial region for inferring a rival's dominance during competitive interactions (Ligneul et al., 2016), which might be partially attributable to this region's role in encoding stable behavioural traits (Hassabis et al., 2013). The amygdala and anterior cingulate cortex (ACC), on the other hand, have been suggested to track moment-to-moment changes in statusbased hierarchies (Kumaran et al., 2012, 2016). The ventral striatum (VS) and ventromedial prefrontal cortex (vmPFC) are highly responsive to competitive outcomes and might thus also contribute to acquire status representations during skill-based contests (Ligneul et al., 2016). Further, these regions show enhanced reactivity to high- as compared to low-status individuals during both competitive (Zink et al., 2008) and non-competitive tasks (Zerubavel et al., 2015). In addition, there is evidence suggesting that the hippocampus encodes relational knowledge of social hierarchies (Kumaran et al., 2012; Schafer and Schiller, 2018; Park et al., 2020), along with regions involved in social cognition such as the precuneus and the temporoparietal junction (TPJ) (Muscatell et al., 2012; Tavares et al., 2015; Zerubavel et al., 2015). Thus, the current neuroscientific evidence permits to formulate a tentative description of how competitive hierarchies are processed in the human brain. First, regions associated with salience detection (amygdala, ACC) capture dominance signals and status changes during social interactions. Second, regions involved in affective valuation (VS, vmPFC) assess an individual's current status and facilitate hierarchy learning on the basis of victories and defeats. Finally, the mentalizing network (precuneus, TPJ, dorsal and rostral $\mathrm{MPFC}$ ) and the hippocampus enable the encoding and implementation of status hierarchies during competitive decision-making. The key question that we addressed here is which role these neurocognitive processes play in status-dependent aggression. We reasoned that the neural substrate of status-processing and aggression should show some degree of overlap, be it in subcortical structures assumed to generate aggressive impulses such as the amygdala (Da Cunha-bang et al., 2017; Buades-Rotger and Krämer, 2018), in those linked with retaliation such as the VS (Chester and DeWall, 2016; Buades-Rotger et al., 2016a), and/or in areas suggested to regulate aggression such as the vmPFC (Buades-Rotger et al., 2019; Bertsch et al., 2020).

A potentially crucial neuromodulator of status-seeking behaviour is the steroid hormone testosterone. Although generally associated with aggression (Geniole et al., 2020), recent evidence indicates that testosterone can flexibly promote prosocial behaviour in order to improve one's social status (Eisenegger et al., 2011; Terburg and van Honk, 2013; Geniole and Carré, 2018). For instance, a study showed that endogenous testosterone was positively associated with generosity in low-status (i.e. junior) rugby players, whereas the relationship was negative in high-status (i.e. senior) players (Inoue et al., 2017). Similarly, men with relatively higher testosterone concentrations punished unfair offers more severely but rewarded fair offers more generously (Dreher et al., 2016). Given that hightestosterone individuals are generally more sensitive to status cues (Josephs et al., 2006; Wagels et al., 2018; Losecaat-Vermeer et al., 2020; Wu et al., 2020; Han et al., 2021) and that competitive situations inherently invoke the use of aggressive strategies (Waddell and Peng, 2014; Dowsett and Jackson, 2019), testosterone might increase competitive aggression by modulating neural reactivity to status signals. Specifically, both preparatory and victory-contingent testosterone surges can induce competitive aggression by activating core neural structures of the threat- and reward-processing systems (i.e. amygdala and VS, respectively) (Geniole and Carré, 2018). Importantly, the effect of testosterone on the neural circuitry of competitive aggression is likely to be more pronounced in men (Zilioli and Bird, 2017), who show stronger endocrine reactivity to competition (Geniole et al., 2017) as well as a tighter association between testosterone and aggression (Geniole et al., 2020). The relationship between status-seeking behaviour and testosterone might however be moderated by cortisol, a stress-related hormone that is thought to partly suppress testosterone's effects (Casto and Edwards, 2016; Dekkers et al., 2019). In the present study, we drew on preexisting sports data, a behavioural study and a neuroimaging study to test (i) whether competitive status is linked with aggression in healthy young men, (ii) whether this is contingent on the neural processing of status signals and (iii) whether testosterone amplifies aggressive and/or neural responses to status cues, either by itself or in interaction with cortisol.

\section{Correlational study}

In a first correlational study, we probed whether competitive status was associated with aggressive play across seasons in soccer, basketball and ice hockey. This proof-of-principle approach allowed us to test the link between competitive status and aggression in real-world settings.

\section{Correlational study: data acquisition}

We defined competitive status as a team's position at the end of the regular season, with higher values indicating a lower standing in the rankings. Aggression was operationalized as the number of fouls (soccer), personal fouls (basketball) or penalty time (ice hockey) incurred relative to received, a measure that accounts for the reciprocal, 'tit-for-tat' character of sports aggression. For basketball and ice hockey, we determined the position of teams from different divisions on the basis of their win percentage. We manually extracted data 
from http://www.footstats.co.uk (soccer), http://www.nba.com (basketball) and http://www.hockey-reference.com (ice hockey) since the last year in which complete, correct, data were available onwards (2000-2008 for European football leagues, 2005 for basketball and hockey). We collapsed these variables separately for the main five European football leagues (England, Spain, Germany, Italy and France), the North-American National Basketball Association league (NBA) and the North-American National Hockey League (NHL) for a total of 2254 observations (i.e. teams in a given season). By using data aggregated over seasons we minimize the effect of proximal situational influences (home-field advantage, referee biases, etc.) that might induce fluctuations in the number of fouls incurred in single games. The correlation between received and committed fouls or penalties was $r_{1412}=0.74$ for football, $r_{418}=0.70$ for basketball and $r_{418}=0.93$ for ice hockey. This indicates that (i) aggressive play follows reciprocal, 'give-and-take' dynamics so that teams who commit more fouls also tend to receive more but (ii) that the ratio of fouls/penalties committed to received captures some unique variance in teams' aggressiveness that is not accounted for by the raw amount of fouls or penalty time incurred. This is thus a valid measure to assess the degree to which a team engages in sanctioned aggression.

\section{Correlational study: data analysis}

Because of the ranked nature of the data, we computed Spearman correlation coefficients between position and foul ratio. We also tested whether this relationship held across seasons and leagues and when accounting for the nested data structure. To do so, we ran linear mixed-effects model analyses with position, season and league as Z-transformed fixed-effect predictors and team as a grouping factor. Following best-practice recommendations (Barr et al., 2013), we attempted to maximize the random-effects structure of the model defining by-team random slopes for all fixed effects and random intercepts for all predictors where possible. The most complex model to converge was one with random slopes for season and random intercepts for league, position and team.

All analyses were performed in $\mathrm{R}$ version 3.6.1 running on R Studio 1.1.423. We used the psych package (Revelle, 2017) for Spearman correlations and ggplot2 for plotting (Wickham, 2016). For linear mixed-effects modelling, we used the lmerTest package (Kuznetsova et al., 2017). Data and analysis scripts for this study are available via the Open Science Foundation (https://osf.io/2jvx4/).

\section{Correlational study: results}

As shown in Figure 1, low ranking was consistently associated with the foul ratio in each individual league as well as across leagues (mean weighted $\rho=0.30$; Cohen's $d=0.63$, $P<0.001$ ). When pooling over all competitions (Figure $1 \mathrm{H}$ ), lowranking teams (Z-transformed position $>1$ ) showed on average a $9.5 \%$ greater foul ratio ( $104.68 \%$ vs $95.18 \%$ ) than high-ranking ones (Z-transformed position<-1). Linear mixed-effects models revealed that the relationship between rank and foul ratio persisted $\left(\beta=0.21, t_{89}=8.80, P<0.001\right)$ when controlling for league and season, which had no effect and did not interact with ranking (all $\mathrm{P}>0.124$; Table 1 ).

\section{Behavioral study}

Our analysis of sports data provides consistent-albeit purely correlational-evidence for a link between low competitive status and aggression at the level of teams. It is however
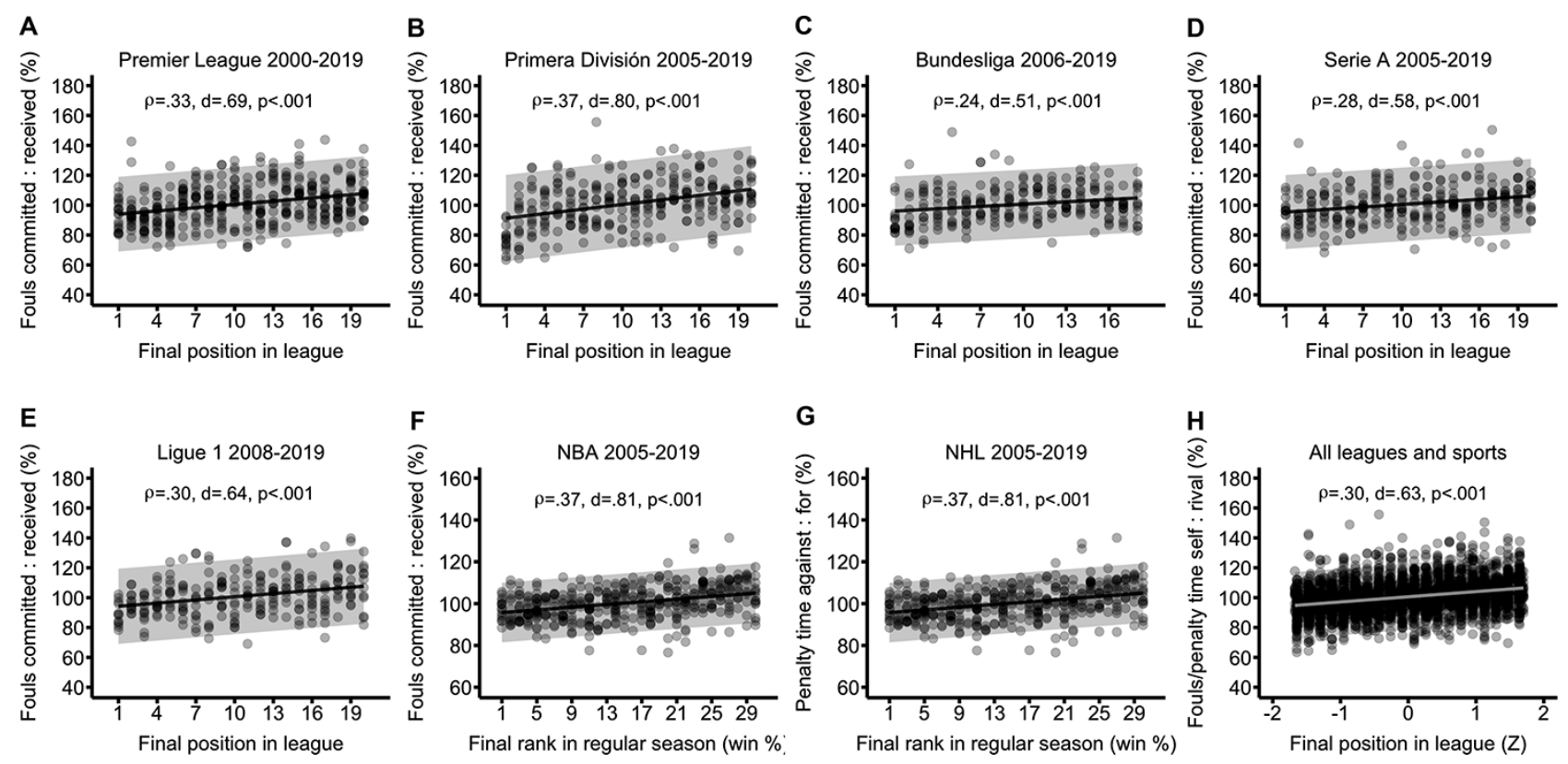

Fig. 1. Correlation between competitive status and aggression in elite sports teams. Status was defined as the team's final position at the end of a season. Aggression was defined as the ratio of fouls (soccer), personal fouls (basketball) or penalty time (ice hockey) incurred relative to received (\%). We collapsed data across seasons. We include best-fit lines and 95\% prediction intervals. (A) English Premier League 2000-19, (B) Spanish Primera División 2005-19, (C) German Bundesliga 2006-19, (D) Italian Serie A 2005-19, (E) French Ligue 1 2008-19, (F) North-American National Basketball Association League 2005-19, (G) North-American National Basketball Association League 2005-19, (H) all data points collapsed, with position expressed as Z-scores. 
Table 1. Results of linear-mixed effects model predicting foul/ penalty ratio in sports teams $(n=2254)$

\begin{tabular}{lllll}
\hline & \multicolumn{5}{c}{ Dependent variable: fouls/ } \\
& penalty time self: rival \\
\cline { 2 - 6 } Predictor & $\beta$ & $\mathrm{SE}$ & $\mathrm{T}$ & $\mathrm{P}$ \\
\hline Position & 0.219 & 0.025 & 8.809 & $<0.001$ \\
League & 0.016 & 0.051 & 0.313 & 0.762 \\
Season & 0.03 & 0.03 & 0.995 & 0.321 \\
Position $\times$ league & 0.028 & 0.018 & 1.537 & 0.124 \\
Position $\times$ season & 0.003 & 0.022 & 0.13 & 0.896 \\
League $\times$ season & 0 & 0.031 & 0.01 & 0.992 \\
Position $\times$ league $\times$ season & 0.032 & 0.019 & 1.667 & 0.096 \\
\hline
\end{tabular}

$\beta$ : regression coefficient, SE: standard error of the regression coefficient, $t$ : t-value, $P$ : $P$-value. Bold values indicate effects significant at $P<0.001$.

unclear whether the status-aggression relationship can also be observed in individual competitors. Moreover, fouls in sports serve a predominantly instrumental function. A more stringent test of our main hypothesis would entail manipulating status experimentally during one-to-one contests in which aggression does not strictly fulfil a competitive purpose, i.e. it does not directly impact rivals' performance. To that end, we ran a preregistered behavioural study (https://osf.io/aq5ge6) in order to probe whether individuals would be more or less aggressive as a function of their competitive status. In order to investigate the effect of status on aggression experimentally, we devised a modified version of the Taylor Aggression Paradigm, a competitive reaction time task in which the winner can choose the volume of a sound blast to punish the loser (Buades-Rotger et al., 2016b). Critically, we manipulated competitive status by programming the task so that subjects won more often against one rival than against the other.

\section{Behavioral study: participants}

As this was an exploratory study, we aimed for a sample size of $n=30$ in order to have $80 \%$ power to detect a middlesized within-subject effect $(d=0.5)$ at a conventional two-sided threshold of $P<0.05$. After exclusion of three participants (two saw through the status manipulation and one failed to understand the task, see protocol below), the sample comprised 25 healthy young men (age: $24 \pm 3.1$; height: $180 \pm 5.1 \mathrm{~cm}$; weight: $75.96 \pm 9 \mathrm{~kg} ; 23$ right-handed, 2 ambidextrous). The study had been approved by the Ethics Committee of the University of Lübeck. Subjects consented to participate and to the anonymized dissemination of the data.

\section{Behavioral study: protocol and task}

Participants were measured in groups of three and believed they would compete against each other, but they actually played against the computer. A male confederate filled in for a participant when an appointment with three subjects was not possible. We first took participants to a computer room in which they provided informed consent and read the instructions together. Computers were separated by screen-walls so that participants could not see each other, and they wore headphones throughout.

We programmed the task so that participants competed in random order, but not more than three times in a row, against each opponent. After eight practice trials, the task started (see Figure 2A for an outline of the task). Trials began with a decision phase wherein subjects saw the percentage of trials won by their current opponent and by themselves as separate filled bars, i.e. their competitive status. During the decision phase, participants set the volume of a sound blast in a 1-8 scale to be later delivered at their opponent should they win a subsequent reaction time task. The chosen volume was our measure of aggression. In the reaction time task, they had to be quicker than their rival in pressing any button when a target appeared (i.e. a bulls eye). We manipulated status so that participants lost more frequently against one rival $(66 \%)$ than against the other (33\%) for a total of 60 trials. To make the setting more believable, subjects were more likely to lose when they were slower than their own median cumulative reaction time, and we interspersed shorter (4 s) and longer (12 s) inter-trial intervals; during the latter, the opponents allegedly played against each other. Following previous work (Buades-Rotger et al., 2016b), we programmed the opponents' punishment selections to increase progressively over time (i.e. every 20 trials) in order to gradually provoke participants.

After the measurement, participants filled out a manipulation check asking how unpleasant they found the loudest and lowest sound blasts to be with a Likert-type scale ranging from 1 to 8 , the perceived average punishment selection of each opponent (also with a Likert type 1 to 8 scale), and the percentage of trials they believed to have won against each opponent. This questionnaire also probed deception success via three open-end questions: 'Did you notice anything special about the behaviour of your fellow players?', 'Did you have a particular strategy for the game?' and 'What do you think was investigated in this study?'. We excluded participants if they made explicit mention to the task being pre-programmed (e.g. 'The other players were bots'), if they misunderstood the task (e.g. not pressing any button in the reaction time task) or if they evinced an insufficient knowledge of the German language. At the end of the experiment, we debriefed participants regarding the goals and methods of the study.

\section{Behavioral study: data analysis}

Average punishment selections show high internal consistency, load onto a single factor (Chester and Lasko, 2019) and predict real-life aggression (King and Russell, 2019), suggesting that they are a valid measure of aggression and that they adequately summarize participant's behaviour in the task. We followed the pre-registered analysis plan (https://osf.io/aq5ge6) and compared mean aggression against the high- vs low-status opponent with a paired t-test in $\mathrm{R}$ (version 3.6.1) running on $\mathrm{R}$ Studio (version 1.1.423). Data and analysis scripts for this study are freely available via the Open Science Foundation (https://osf.io/2jvx4/).

\section{Behavioral study: results}

Post-experimental manipulation checks revealed that they were aware of winning less often $\left(t_{24}=7.55, d=1.51, P<0.001\right)$ against the better-performing player $(34.8 \% \pm 2.1 \%$ [mean \pm standard error]) than against the worse one $(60.5 \% \pm 1.9 \%)$. As intended, they did not perceive either rival to be more aggressive than the other $\left(t_{24}=1.58, P=0.125\right)$. Following the pre-registered analysis plan (https://osf.io/aq5ge6), we extracted mean punishment selections per condition and compared them with a paired $t$ test. Subjects selected louder sound blasts in a low- than in a high-status position $\left(t_{24}=2.66, d=0.54, P=0.013\right.$; Figure $\left.2 B\right)$. 
A
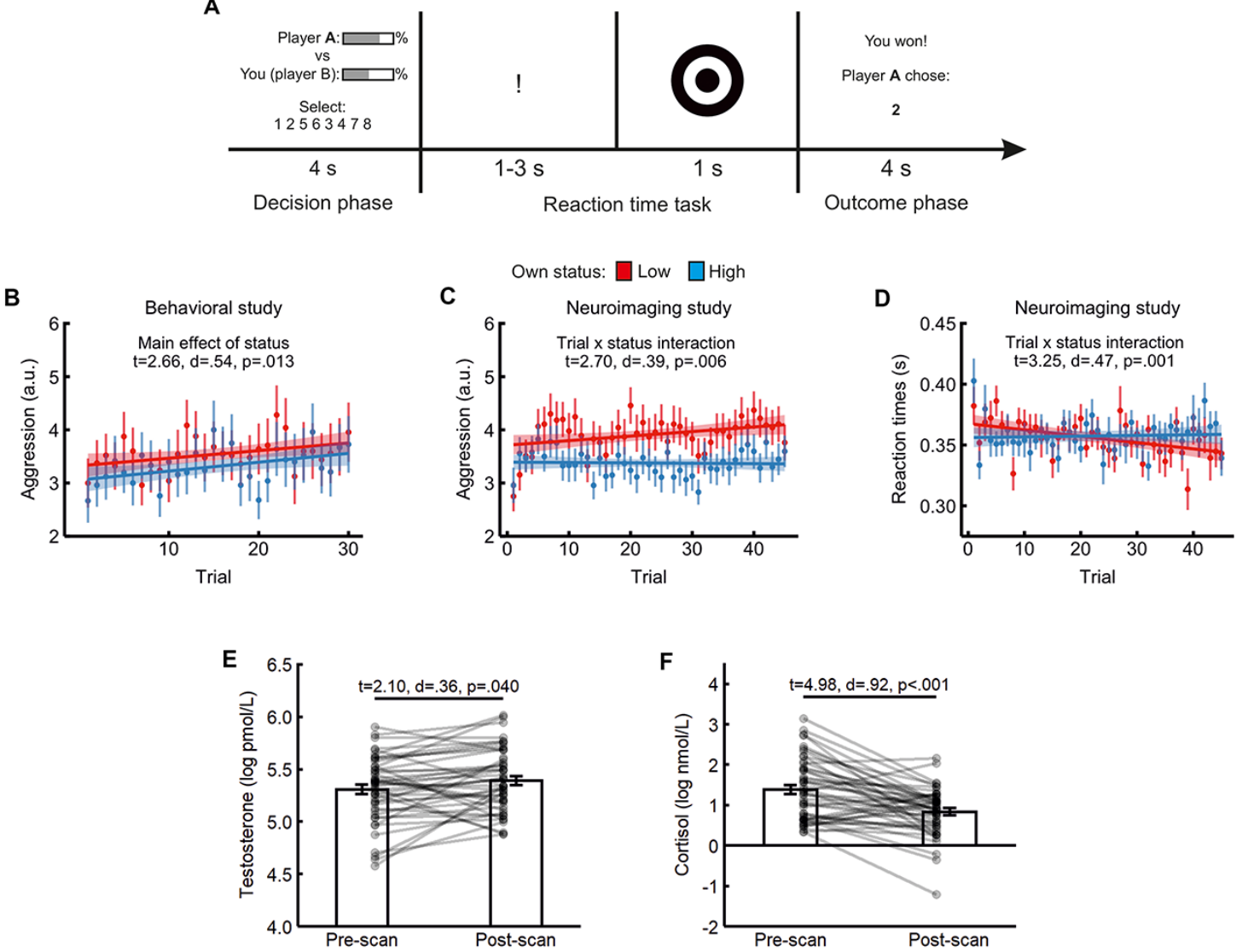

Fig. 2. (A) Outline of the task. Subjects saw the \% of victories achieved by the opponent and themselves as a filled bar while choosing the volume of a sound blast to be later directed at their opponent (decision phase). Then, they had to be faster than the rival in pressing a button when a jittered bullseye appeared (reaction time task). In the outcome phase they were informed of whether they won or lost and of the rival's selection. If they lost, they received the sound blast at the end of the trial via headphones. They were consistently worse against one opponent (low-status condition) and better than the other (high-status condition), though both rivals chose equally strong sound blasts on average. (B) mean punishment selections by trial and participant status in the behavioral study, including best-fit lines and $95 \%$ prediction intervals. (C) mean aggression by trial and participant status in the neuroimaging study, including best-fit lines and $95 \%$ prediction intervals. (D) mean response latency in the reaction time task by trial and participant status in the neuroimaging experiment. (E) testosterone levels in saliva pre- and post-scanning. ( $\mathrm{F}$ ) cortisol levels in saliva pre- and post-scanning.

\section{Neuroimaging study}

In a subsequent neuroimaging study, we used a slightly modified version of the same task to scrutinize neural responses to status information during a competitive interaction. Further, we tested whether status-related brain activity was linked with actual aggressive behaviour in the task as well as with salivary testosterone and cortisol measured before and after scanning. Unlike the behavioural study, we programmed opponents' punishments to stay relatively constant over time. We did so in order to disentangle provocation and status effects and to render trials more comparable throughout the task for subsequent averaging of brain activity. We hence set the opponents to select punishments in the middle range (3-6) throughout the task instead of increasing progressively. We also lengthened the task for a total of 90 trials, divided in three runs of 30 trials each (15 per opponent) to increase statistical power. In this case, the opponents were always confederates of the experimenters who pretended to play against the participant from computers outside the scanner. To increase the plausibility of this setting, participants played the eight practice trials together with the confederates in the same computer room where the pilot measurements had taken place.

\section{Neuroimaging study: participants}

We determined the sample size on the basis of a previous study $(n=39)$ in which we observed middle-sized correlations $(r \approx 0.4)$ between endogenous testosterone, aggression and brain activity using a similar task (Buades-Rotger et al., 2016b). We thus aimed for a sample size of 50 , which yields $~ 80 \%$ power to detect effects of $r=0.4$ or larger with a two-sided threshold of $P<0.05$. After exclusion of six subjects due to non-deception $(n=4)$ and failure to understand the task $(n=2)$, the final sample comprised 47 men aged $24 \pm 3.8$ (height: $182 \pm 6.6 \mathrm{~cm}$; weight: $79.90 \pm 11 \mathrm{~kg} ; 37$ right-handed, 7 left-handed, 3 ambidextrous) who were reportedly free of current psychiatric, neurological and endocrine diseases except for one participant with treated hypothyroidism. We included left-handed participants because we did not have specific hypotheses regarding lateralization of the effects and because subjects used both hands to perform the task. This study had also been approved by the Ethics Committee of the University of Lübeck. Subjects provided informed consent for participation and anonymized dissemination of the data. We used the same post-experimental questionnaire as in the behavioural study, and we debriefed them regarding the goals and methods of the study. Measurements began between 
12 and 15 PM in order to minimize circadian fluctuations in hormonal levels, with the exception of two measurements (17 and $18 \mathrm{PM})$ that could not be scheduled otherwise.

\section{Neuroimaging study: acquisition of testosterone and cortisol data}

Subjects provided saliva samples in plastic vials (SafeSeal micro-tube $2 \mathrm{ml}$ from Sarstedt) with the passive drooling technique before and after scanning. We froze the samples at $-20^{\circ} \mathrm{C}$ and shipped them in dry ice to author BGK's laboratory in Manchester (UK) for analysis once study was completed. Free testosterone and cortisol concentrations were estimated with liquid chromatography tandem mass spectrometry (LC-MS/MS) as described elsewhere (Perogamvros et al., 2009; Keevil et al., 2013). Coefficients of variation (CVs) with this technique have been reported to be $5.3 \%$ for testosterone and $8.7 \%$ for cortisol, whereas mean inter-assay CVs were $9 \%$ for testosterone and 7.8\% for cortisol (Perogamvros et al., 2009; Keevil et al., 2013). The lower limits of quantification were $5 \mathrm{pmol} / \mathrm{L}$ for testosterone and $0.8 \mathrm{nmol} / \mathrm{L}$ for cortisol.

\section{Neuroimaging study: acquisition of fMRI data}

We acquired all scans with a 64-channel head-coil mounted on a 3T Siemens Magnetom Skyra scanner at the Center for Brain, Behavior and Metabolism at the University of Lübeck. For functional volumes, we applied a single-shot gradient-recalled echo-planar imaging sequence sensitive to blood oxygen level dependent contrast $\left(\mathrm{TR}=1060 \mathrm{~ms}\right.$; $\mathrm{TE}=30 \mathrm{~ms}$; flip angle $=60^{\circ}$; 60 transversal slices; slice thickness $3 \mathrm{~mm}$; in-plane voxel size $=3 \times 3 \mathrm{~mm}^{2}$; field-of-view [FOV] $=210 \times 210 \mathrm{~mm}^{2}$, simultaneous multi-slice factor $=4$; full-brain coverage). We acquired 570 volumes per run for a total of three runs $(\approx 30 \mathrm{~min})$. Before and after the task we acquired two magnetic field measurements (2D double-echo gradient-echo sequence; $\mathrm{TE}_{1}=5,17 \mathrm{~ms}$; $\mathrm{TE}_{2}=7.63 \mathrm{~ms} ; \mathrm{TR}=554 \mathrm{~ms} ;$ flip angle $=60^{\circ} ; 50$ transversal slices; slice thickness $3 \mathrm{~mm}$; in-plane voxel size $=3 \times 3 \mathrm{~mm}^{2}$; FOV $=240 \times 240 \mathrm{~mm}^{2}$ ) for subsequent offline distortion correction as well as two $6.5 \mathrm{~min}$ eyes-closed resting-state runs not analysed for the present manuscript. We further acquired an anatomical scan at the start of each measurement applying a 3D T1-weighted Magnetization Prepared-RApid Gradient Echo sequence $(\mathrm{TR}=2300 \mathrm{~ms} ; \mathrm{TE}=2.94 \mathrm{~ms} ; \mathrm{TI}=900 \mathrm{~ms}$; flip angle $=9^{\circ}$; voxel size $=1 \times 1 \times 1 \mathrm{~mm}^{3} ;$ FOV $=320 \times 320 \mathrm{~mm}^{2}$ ).

\section{Neuroimaging study: analysis of behavioural and hormonal data}

For the analysis of behavioural data, we first ran a paired t-test comparing mean aggression against in the low- us high-status condition as we had done in the behavioural study. Additionally, we ran linear mixed-effects models on participants' aggressive behaviour, decision latencies and reaction times. We specifically tested for effects of opponent status (high or low), trial number ( 1 to 45 ) and outcome of the previous trial (won or lost). These three variables were defined as fixed effects, whereas subject was defined as random effect. We included by-participant slopes for all fixed effects and random intercepts for all predictors where possible, adhering to standard guidelines for linear mixed-effects modelling (Barr et al., 2013). Models with random slopes for outcome failed to converge, just as those with random intercepts for status and outcome. Therefore, all models included random intercepts for subject and trial as well as random by-participant slopes for status and trial. We performed these analyses using the lmerTest package (Kuznetsova et al., 2017) in $R$ (version 3.6.1) running on $R$ Studio (version 1.1.423).

For testosterone and cortisol, we compared the pre- and post-scan log-transformed values using paired t-tests in order to inspect for state changes in hormonal concentrations. Two pre-scan testosterone samples had to be discarded because the amount of saliva did not suffice for reliable quantification. We then tested whether mean aggression against the highminus the low-status opponent was associated with baseline testosterone, cortisol, the testosterone-to-cortisol ratio and/or pre-post changes in either hormone using Pearson correlation coefficients. For paired t-tests, we report Cohen's $d_{r m}$, which accounts for the correlation between repeated measurements (Lakens, 2013). For correlation and regression coefficients, we converted the corresponding $r$ and t-values to Cohen's $d$ using the psych package's functions $t 2 d$ and $r 2 d$ respectively (Revelle, 2017). We used ggplot2 to plot results (Wickham, 2016).

\section{Neuroimaging study: analysis of fMRI data}

We performed the pre-processing and analysis of neuroimaging data using Statistical Parametric Mapping 12 (SPM12; https:// www.fil.ion.ucl.ac.uk/spm/) running on Matlab 2019b. We used a standard pre-processing pipeline that involved, in this order, slice-timing correction to the four middle slices (i.e. those acquired at $485 \mathrm{~ms}$ ) with a fourth degree spline interpolation, realignment to the first functional volume, coregistration of mean functional and anatomical images, segmentation of the anatomical images based on default tissue probability maps, normalization to the Montreal Neurological Institute (MNI) template and smoothing with an $8 \mathrm{~mm}$ full-width at half-maximum Gaussian kernel. Additionally, we performed distortion correction using the FieldMap toolbox, except in seven participants for which this procedure failed or worsened image quality. We excluded one imaging run in three subjects due to excessive head movements $\left(>3 \mathrm{~mm}\right.$ or $3^{\circ}$ in any direction).

First-level models comprised two regressors for the decision phase (high- or low-status opponent; $4 \mathrm{~s}$ ) and four for the outcome phase (won or lost us high- or low-status; $4 \mathrm{~s}$ ). We also included the absolute distance in status between subject and opponent in percentage as a covariate in the decision phase to control for momentary fluctuations in status. As regressors of no interest, we modelled the warning sign, target and motor responses in the reaction time task as well as the sound at the end of the outcome phase as delta functions with null duration. We further included the six movement parameters estimated from realignment ( $x, y, z$, pitch, roll and yaw). We convolved all regressors (except for motion parameters) with the canonical hemodynamic response function, implemented a high-pass filter with a $128 \mathrm{~s}$ cut-off and applied the standard SPM autoregressive model AR(1) to control for autocorrelation. In order to inspect for trial-wise changes in activity associated with aggression, we additionally defined identical first-level models that included trial-wise mean-centred punishment selections as parametric modulator.

We first performed multi-voxel pattern analyses (MVPA) to uncover local activation patterns that most differentiated between the two opponents in the decision phase. We used the Decoding Toolbox (Hebart et al., 2015) running on Matlab $2019 \mathrm{~b}$ to implement a linear support vector machine algorithm that classifies multivariate activation patterns for each condition and run using a leave-one-out cross-validation procedure on the corresponding beta images. We ran such an analysis 
within each of eight regions of interest (ROIs) putatively involved in the relational processing of social status (Zerubavel et al., 2015; Qu et al., 2017; Schafer and Schiller, 2018). We defined these ROIs as bilateral anatomical masks extracted from the Automatic Anatomical Labelling atlas (Maldjian et al., 2003): the amygdala (merge of left and right 'Amygdala' masks), anterior cingulate cortex ('Cingulum_Ant' mask), dorsomedial prefrontal cortex ('Frontal_Sup_Medial' mask), hippocampus (merge of left and right 'Hippocampus' masks), precuneus ('Precuneus' mask), striatum (merge of 'Caudate', 'Putamen' and 'Pallidum' masks), temporal-parietal junction (merge of 'Temporal_Sup' and 'SupraMarginal' masks) and ventromedial prefrontal cortex (merge of left and right 'Rectus' and 'Frontal_Med_Orb' masks). We resampled the masks to match the voxel size of the functional data $(3 \mathrm{~mm})$. For each of these regions, we extracted the participant-wise area under the curve (AUC) minus chance as a classification performance measure. Here, AUC expresses the total surface below the receiver-operating characteristic curve, which is obtained by plotting the cumulative true positive rates against the cumulative false positive rates. Hence, higher AUC values indicate a greater capacity to classify between categories. While standard accuracy measures treat all classifications equally, AUC also takes into account the 'confidence' (i.e. the distance to the decision boundary) that the classifier has regarding the membership of specific items (Hebart et al., 2015). In order to assess statistically which ROIs distinguished between conditions, we computed the bootstrapped $95 \%$ bias-corrected accelerated confidence intervals (BCa CIs) of the average AUC for each ROI. ROIs whose CI did not include zero were considered to classify between the high- and low-status rival at an above-chance level. In order to more precisely localize the observed effects, we performed a post-hoc searchlight analysis (9-voxel radius sphere) within each ROI showing above-chance classification. These analyses were thresholded at $P<0.05, k>50$ uncorrected.

We subsequently sought for associations between neural reactivity to status signals and aggression on a within-subject basis. We did so by comparing the parametric modulator for punishment selections in the low- vs the high-status condition using a paired t-test. This analysis tests for brain areas showing transient increases in activity as a function of participants' trial-wise aggression levels against one opponent relative to the other. Five participants had to be excluded from this analysis due to lack of variability in behaviour (i.e. they chose the same punishment in all trials). Given that we had no a priori hypotheses for these analyses, we applied a threshold of $P<0.001$ at the voxel level with a $P<0.05$ family-wise error (FWE) correction at the cluster level.

In the outcome phase, we tested whether wins and losses were differentially processed depending on status using a flexible factorial analysis. First, we tested the main effects of won us lost in order to reproduce the VS and vmPFC activity commonly observed during competitive victories. Because subjects lost more often against one of the two opponents, status and outcome were not orthogonal. We therefore did not inspect the main effect of status. Rather, we directly tested the interaction between the two factors, namely, the contrast [won high + lost low] > [lost high + won low] and its opposite using paired ttests (Supplementary Table S1 in Supplementary Material), and post-hoc plotted the resulting parameter estimates. For these contrasts, we also set a voxel-level $P<0.001$ threshold with a cluster-wise pFWE $<0.05$ correction, as the effect of competitive outcomes on the targeted valuation areas is usually detectable in whole-brain analyses (Votinov et al., 2015; Ligneul et al., 2016).
Finally, we probed whether interindividual differences in status-based aggression were associated with the neural processing of status signals. We used MarsBaR (http:// marsbar.sourceforge.net/) to extract subject-wise parameter estimates from ROIs showing above-chance classification in the MVPA analyses (whole ROI) and from clusters showing significant activity in the outcome by status interaction $(6 \mathrm{~mm}$ sphere around peak coordinate). We computed the correlation coefficients between activity in each ROI/cluster and mean aggression against the high- minus the low-status opponent. We also computed the $95 \%$ bootstrapped CIs for the correlation coefficients of significant associations $(P<0.05)$ in order to assess their robustness and to protect against the influence of outlying observations. We performed all bootstrapping analyses using the bootstrap package (version 2019.5) in $\mathrm{R}$ (version 3.6.1) running on $R$ Studio (version 1.1.423). We used ggplot2 to depict all neuroimaging results (Wickham, 2016). Behavioral and ROI data along with analysis scripts for this study are freely available via the Open Science Foundation (https://osf.io/2jvx4/). Raw and pre-processed neuroimaging data are available upon request.

\section{Neuroimaging study: behavioural results}

Participants were 47 healthy young men (age $=24 \pm 3.8$ [mean \pm standard deviation]) who believed to be playing against two other participants. These were actually confederates and the task was again preprogramed. Here, the status manipulation was also successful, as subjects were aware of winning less often against the stronger than against the weaker rival $\left(t_{46}=10.05\right.$, $d=2.36, P<0.001)$. Subjects overestimated the percent of trials won against both the better $(41.1 \% \pm 1.6 \%$ [mean \pm standard error] us $\left.33 \%, t_{46}=4.74, d=0.69, P<0.001\right)$ and worse opponents $\left(71.9 \% \pm 1.7 \%\right.$ vs $\left.66 \%, t_{46}=3.40, d=0.49, P=0.001\right)$. Again, they did not perceive the stronger opponent to be more aggressive $\left(t_{46}=1.26, d=0.27, P=0.213\right)$. As in the pilot study, subjects selected higher average punishments against when they were in a low- than in a high-status position $\left(t_{46}=3.57, d=0.57, P<0.001\right.$; Figure 2C). We thus calculated status-dependent aggression as the difference in average punishment selections in each condition (low minus high status) to be used in later correlation analyses with neural and hormonal data.

We additionally tested whether subjects' behaviour changed over time using linear mixed-effects models (see Methods). Participants selected louder sound blasts over time when they were in a low-status position, whereas their punishment selections remained unchanged in a high-status one (status $\times$ trial interaction: $\beta=0.125, t_{4062}=2.70, P=0.006$; Figure $2 C$; Table $\left.2 A\right)$. Specifically, they evinced an increase of around 0.7 points $(\approx 8.75 \%$ of the scale) in the last $(4.09 \pm 0.08$ [mean \pm standard error]) compared to the first five trials $(3.39 \pm 0.21)$ when low in status. In contrast, their average aggression levels remained virtually unchanged as high-status players (first five trials: $3.47 \pm 0.14$; last five trials: $3.49 \pm 0.07$ ). Thus, participants selected stronger punishments in a low rank even when provocation remained constant.

Response latency in the decision phase did not vary as a function of status, time or their interaction (all $\mathrm{P}>0.154$; Table 2B). That is, subjects took similarly long to choose the punishment against either opponent across trials (high status: $1.32 \pm 0.16 \mathrm{~s}$; low status: $1.29 \pm 0.12 \mathrm{~s})$. Nevertheless, there was a significant main effect of outcome $\left(\beta=0.032 \pm 0.01, t_{1073}=2.34, P=0.019\right)$ such that participants chose about $50 \mathrm{~ms}$ faster after losing $(1.27 \pm 0.01 \mathrm{~ms})$ than after winning $(1.32 \pm 0.01 \mathrm{~s})$. 
Table 2. Results of linear-mixed effects models in the neuroimaging study $(n=47)$

\begin{tabular}{|c|c|c|c|c|}
\hline Predictor & $\beta$ & SE & $t$ & $P$ \\
\hline \multicolumn{5}{|c|}{ a) Dependent variable: punishment selections } \\
\hline Status & 0.488 & 0.146 & 3.347 & 0.002 \\
\hline Trial & 0.141 & 0.059 & 2.383 & 0.020 \\
\hline Outcome & 0.005 & 0.035 & 0.132 & 0.895 \\
\hline Status $\times$ Trial & 0.125 & 0.046 & 2.708 & 0.007 \\
\hline Status $\times$ Outcome & 0.014 & 0.048 & 0.288 & 0.773 \\
\hline Trial $\times$ Outcome & 0.049 & 0.035 & 1.394 & 0.164 \\
\hline Status $\times$ Trial $\times$ Outcome & 0.041 & 0.048 & 0.85 & 0.395 \\
\hline \multicolumn{5}{|c|}{ b) Dependent variable: response latency in decision phase } \\
\hline Status & 0.026 & 0.018 & 1.426 & 0.154 \\
\hline Trial & 0.020 & 0.020 & 0.977 & 0.331 \\
\hline Outcome & 0.032 & 0.013 & 2.346 & 0.019 \\
\hline Status $\times$ Trial & 0.023 & 0.018 & 1.261 & 0.207 \\
\hline Trial $\times$ Outcome & 0.008 & 0.014 & 0.606 & 0.545 \\
\hline Status $\times$ Trial $\times$ Outcome & 0.003 & 0.019 & 0.168 & 0.867 \\
\hline \multicolumn{5}{|c|}{ c) Dependent variable: response latency in reaction time task } \\
\hline Status & 0.001 & 0.003 & 0.591 & 0.554 \\
\hline Trial & 0.007 & 0.002 & 2.989 & 0.004 \\
\hline Outcome & 0.002 & 0.002 & 1.097 & 0.273 \\
\hline Status $\times$ Trial & 0.008 & 0.002 & 3.258 & 0.001 \\
\hline Status $\times$ Outcome & 0.002 & 0.003 & 0.656 & 0.512 \\
\hline Trial $\times$ Outcome & 0.002 & 0.002 & 0.821 & 0.412 \\
\hline Status $\times$ Trial $\times$ Outcome & 0.002 & 0.003 & 0.737 & 0.461 \\
\hline
\end{tabular}

$\beta$ : regression coefficient, $\mathrm{SE}=$ standard error, $t$ : $t$-value, $P$ : $P$-value. Bold values indicate effects significant at $P<0.05$.

In the reaction time task, participants became progressively quicker as low-status players (status-by-trial interaction: $\beta=0.008, t_{4111}=3.25, P=0.001$; Figure $2 \mathrm{D}$; Table $2 \mathrm{C}$ ). On average, subjects were $\sim 22 \mathrm{~ms}$ faster in the last five $(3.50 \pm$ $0.03 \mathrm{~s})$ relative to the first five trials $(3.72 \pm 0.06 \mathrm{~s})$ against when they had a low status, whereas they were comparably quick throughout the task in the high-status condition (first five trials: $3.64 \pm 0.12 \mathrm{~s}$ and last five trials: $3.65 \pm 0.06 \mathrm{~s}$ ). This confirms the motivational relevance of competitive status for participants' performance.

\section{Neuroimaging study: testosterone and cortisol results}

Concerning hormonal concentrations, average testosterone levels increased $1.57 \%$ after scanning $\left(t_{44}=2.10, d=0.36\right.$, $P=0.040$; Figure 2D), whereas mean cortisol decreased by $39.74 \%$ $\left(t_{46}=4.96, d=0.92, P<0.001\right.$; Figure $\left.2 \mathrm{E}\right)$. Baseline concentrations of testosterone $\left(r_{43}=0.08, P=0.595\right)$ or cortisol $\left(r_{45}=-0.01\right.$, $P=0.973$ ) were neither associated with aggression nor with the baseline testosterone-to-cortisol ratio $\left(r_{43}=0.10, P=0.497\right)$ or the pre-post-change in either hormone (testosterone: $r_{43}=0.07$, $P=0.627$; cortisol: $r_{45}=0.06, P=0.686$ ). Therefore, we did not use endogenous hormone levels for further analyses.

\section{Neuroimaging study: status-dependent activity patterns during punishment selection}

With regard to neuroimaging data, we first tested whether ROIs previously linked to the processing of status signals also encode competitive status during decisions to aggress (Figure 3A). To that end, we performed MVPA in the decision phase (see Methods). This revealed that the striatum and hippocampus distinguished between opponents (Figure 3B). That is, multivariate activity patterns in these regions could classify at an above-chance level whether subjects were facing the high- or the low-status opponent. Post-hoc searchlight analyses showed that both ventral and dorsal aspects of the left striatum contributed to the effect, whereas in the case of the hippocampus classification was most strongly driven by its right anterior portion (Figure 3C). We then tested whether a stronger multivariate differentiation between opponents was linked with status-dependent aggression across subjects. To do so, we took classification performance values for the hippocampus and striatum and correlated them with mean aggression against the high- minus low-status opponent. Although we observed no effects for the hippocampus $\left(r_{45}=-0.03, P=0.823\right)$, there was an association between striatum activity patterns and aggression against the high- minus low-status rival $\left(r_{45}=0.29, d=0.62\right.$, $P=0.043$; Figure $3 D$ ). In other words, subjects showing a more pronounced differentiation between opponents in the striatum showed greater status-contingent aggressive behaviour.

\section{Neuroimaging study: trial-by-trial fluctuations in punishment selections}

We subsequently inquired whether neural reactivity to status cues influenced punishment selections on a within-subject basis. We hence performed a parametric modulation analysis comparing trial-wise decisions against in each condition (see Methods). As shown in Figure 3E, greater aggression against in a low-compared to a high-status position was associated with increased activity in vmPFC $(t=4.57, k=59, x=9, y=50, z=-10$; Figure 3B), dorsolateral prefrontal cortex (dlPFC; $t=4.11, k=57$, $x=21, y=44, z=41$ ), ventrolateral prefrontal cortex (vlPFC; $\mathrm{t}=4.79, k=57, \mathrm{x}=-33, \mathrm{y}=32, \mathrm{z}=-16$ ) and superior parietal lobe (SPL; $t=4.80, k=88, x=-24, y=-76, z=47$ ). That is, activity in these regions co-varied with participants' aggressive behaviour in a low- relative to a high-status rank. No regions survived in the opposite contrast (high $>$ low). 
A Regions-of-interest for multi-voxel pattern analysis

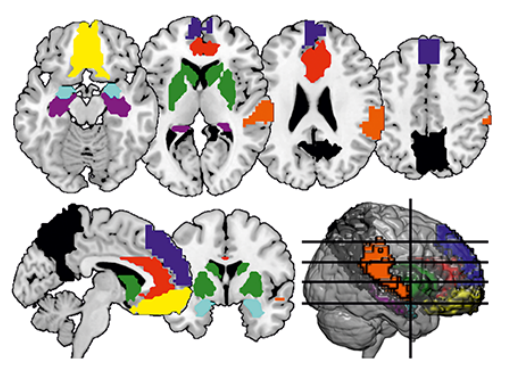

D

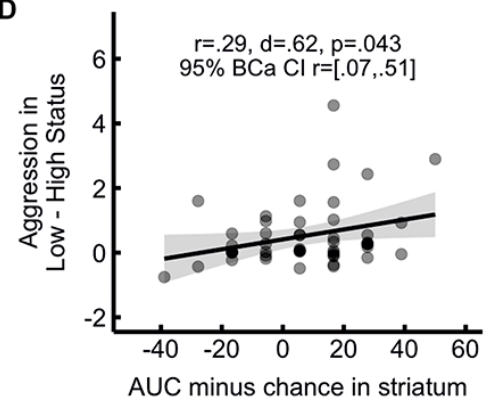

B

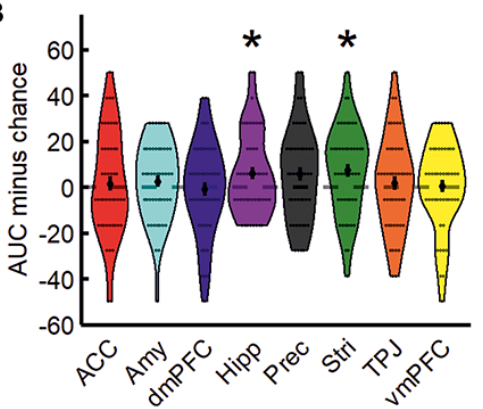

E Parametric modulation

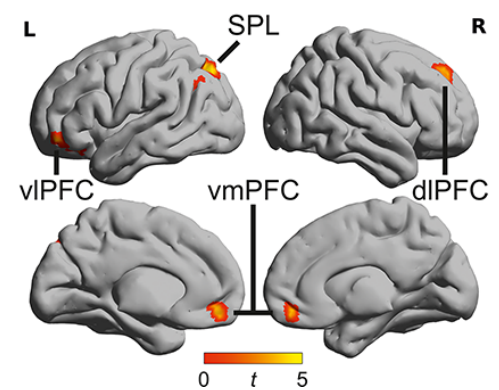

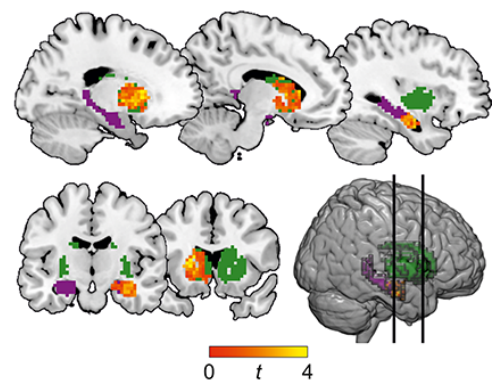

$\mathbf{F}$

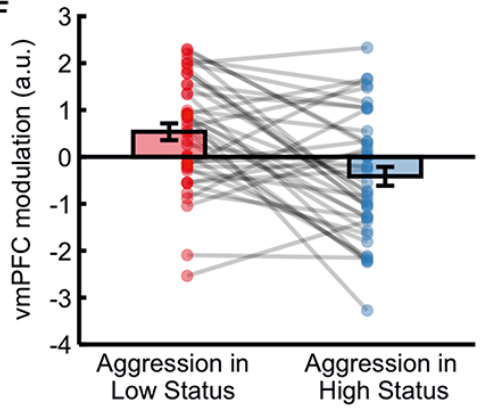

Fig. 3. Neural processing of competitive status during punishment selection (decision phase). (A) ROIs used in MVPA to identify multivariate status representations during punishment selection. (B) classification performance expressed as AUC minus chance per each ROI. Each dot shows the AUC value per subject, with higher values indicating better classification between the better- and worse-performing rivals. Asterisks denote ROIs with significant above-chance accuracy according to bootstrap resampling. ACC: anterior cingulate cortex; Amy: amygdala; dmPFC: dorsomedial prefrontal cortex; Hipp: hippocampus; Prec: precuneus; Stri: striatum; TPJ: temporalparietal junction; vmPFC: ventromedial prefrontal cortex. (C) results of the post-hoc searchlight MVPA analysis within hippocampus and striatum masks (voxel-level $P<0.05$ uncorrected, cluster size $k>50$ ). Higher values indicate a greater contribution to the classification. (D) correlation between classification performance in the striatum and mean aggression against the high- minus low-status opponent. We include best-fit lines and $95 \%$ prediction intervals. $r=$ Pearson correlation coefficient; $d=$ Cohen's $d ; 95 \%$ BCa CI: 95\% BCa CIs. (E) parametric modulation in the decision phase (voxel-level $P<0.001$, cluster-level $P<0.05 \mathrm{FWE}$ corrected, $n=42$ ). Higher values indicate more trial-wise activity as a function of aggression in a low- relative to a high-status position. dlPFC: dorsolateral prefrontal cortex; SPL: superior parietal lobe; vlPFC: ventrolateral prefrontal cortex. (F) parameter estimates resulting from the parametric modulation in the vmPFC. A.u.: arbitrary units.

\section{Neuroimaging study: neural processing of competitive outcomes as a function of status}

In the outcome phase, we observed widespread activation in the contrast won $>$ lost with peaks in the bilateral VS (Supplementary Table S1 in Supplementary Material). This is in line with previous results employing competitive tasks (Votinov et al., 2015; Buades-Rotger et al., 2016a). More importantly, we tested the interaction between status and outcome in order to inspect whether victories and defeats were differently processed in the low- compared to the high-status condition. The interaction contrast [won low + lost high)] > [lost high + won low] revealed activation in left anterior insula (AI), dorsal anterior cingulate cortex (dACC), left dorsolateral prefrontal cortex (dlPFC), left and right TPJ, precuneus and VS (Figure 4A-C; Supplementary Table S1 in Supplementary Material for complete results). These regions hence reacted more strongly to infrequent, statusincongruent outcomes. However, as becomes apparent from the parameter estimates in the VS and dACC (Figure 4B-C), the interaction was driven by a stronger effect of the outcome when playing against the high- relative to the low-status opponent. If the effect were merely driven by the infrequency or unpredictability of events, activity should be also increased in lost relative to won trials against the low-status opponent, which was not the case. The opposite contrast, which entailed expectable, status-congruent outcomes, yielded activation in primary visual and inferior temporal cortex as well as a cluster in the brainstem (Supplementary Table S1 in the Supplementary Material).
We next probed whether the neural processing of victories and defeats was linked with status-dependent aggressive behaviour. We therefore extracted parameter estimates from clusters resulting from the [won high + lost low)] $>$ [lost high + won low] contrast (dACC, AI, dlPFC, left and right TPJ, precuneus and VS) and correlated them with the status effect on aggression. Specifically, we extracted the high-minus low-status difference separately for victories and defeats. Because we performed 14 correlations (two values for each of seven ROIs), we applied a Bonferroni correction to control for multiple comparisons $(0.05 / 14=0.003)$. Differential reactivity to victories in the dACC was significantly associated with aggression against the high- minus the low-status opponent $\left(r_{45}=0.45\right.$, $d=1.02, P=0.001$; Figure $4 D)$. There was no correlation for losses $\left(r_{45}=0.12, P=0.394\right)$. Activity in the rest of ROIs (AI, dlPFC, left and right TPJ and VS) was not associated with status-dependent aggression at a corrected level (all $P>0.050$; Supplementary Table S2 in Supplementary material).

\section{Discussion}

\section{Low competitive status is associated with aggression}

Aggressiveness is often taken as a requisite for competitive success (Chow et al., 2009; Trebicky et al., 2013; Waasdorp et al., 2013; Laustsen and Petersen, 2017; Cheng, 2020; Weick, 2020). However, better contenders can rely on their skill, whereas less successful ones may use aggression to hamper rivals' 
A

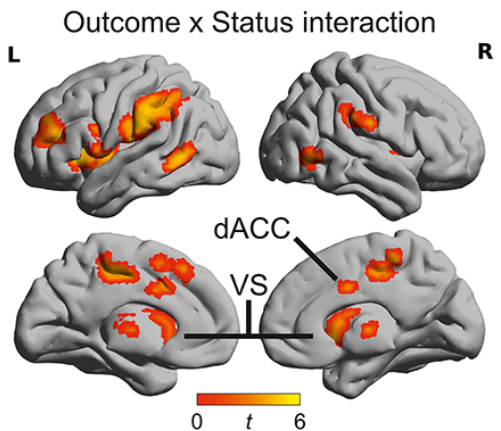

C

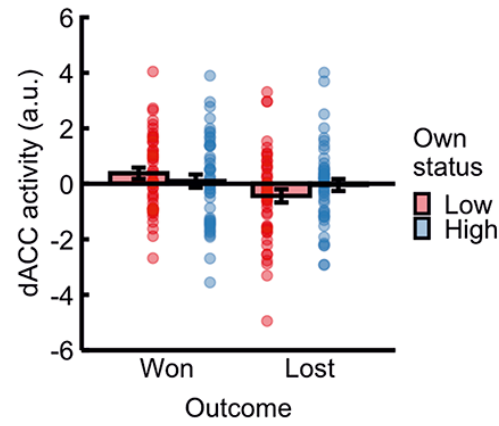

B

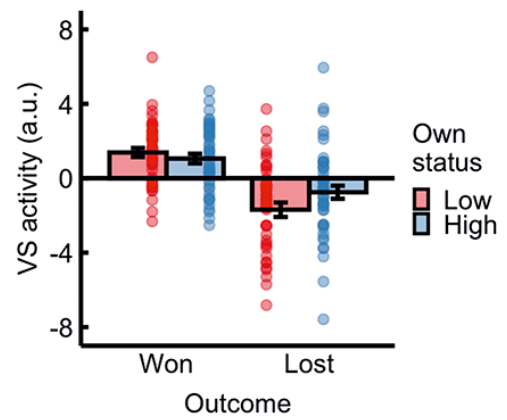

D

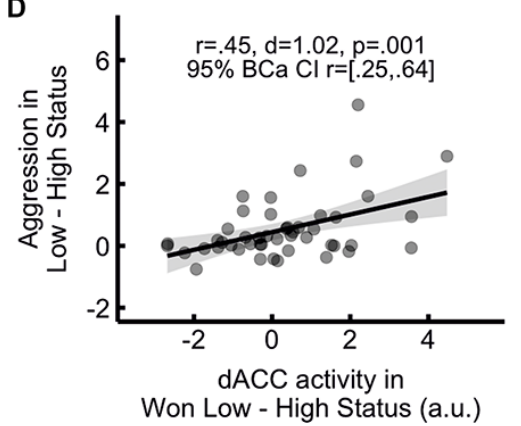

Fig. 4. Neural processing of competitive victories and defeats (outcome phase). (A) regions showing a significant interaction between status and outcome (voxellevel $P<0.001$, cluster-level $P<0.05$ FWE corrected). (B) parameter estimates for the interaction effect in the VS. (C) parameter estimates for the interaction effect in the dACC. (D) correlation between AACC reactivity to victories and aggression in the low- minus high-status condition, including best-fit lines and $95 \%$ prediction intervals. $r=$ Pearson correlation coefficient; $d=$ Cohen's $d ; 95 \%$ BCa CI.

progress (Kirker et al., 2000; Coulomb-Cabagno and Rascle, 2006). Moreover, the frustration and loss of control entailed in being repeatedly defeated should facilitate rather than suppress aggression in low-status contestants (Przybylski et al., 2014; Yu et al., 2014; Oxford et al., 2017). In a correlational analysis and two laboratory experiments, we found that low competitive status, measured as competitors' relative rank in a hierarchy, was linked with more frequent and intense aggressive behaviour. Our results replicate and extend previous investigations showing that fouls or penalties are associated with worse overall team performance in American football (Hauge, 2012), ice hockey (Coates et al., 2012), soccer (Jewell, 2012) and basketball (Berri and Rodenberg, 2012). Unlike these studies, however, our measure of aggression (fouls or penalties committed relative to received) captures the reciprocal nature of aggressive play and thus provides clearer evidence on the status-aggression relationship.

The findings from our two experimental studies further show that the link between low status and aggression holds in competitions between individuals (i.e. not only between teams) and when aggressive behaviour does not directly offer a clear competitive advantage. In addition, in our neuroimaging experiment subjects became quicker and selected louder sound blasts over time against in a low-status position, even when the opponents' hostile intent remained constant over time. This finding further demonstrates that aggression increases as competitive hierarchies emerge and is not a mere correlate of low performance. Our results also imply that the relationship between competitive status and aggression is not limited to situations involving face-to-face competition but also applies to virtual, indirect contests. In line with this assumption, an online bargaining study showed that individuals attribute more hostile intentions to higher-status opponents (Saalfeld et al., 2018). Competitive status thus appears to be a relevant trigger for aggressive behaviour in both direct and virtual interactions.

Our main finding that participants chose higher punishments when placed in a low rank is however not entirely expectable. After all, participants might have instead displayed the opposite pattern, i.e. punishing a weaker rival to assert their dominance while being less aggressive against a stronger opponent as a conciliatory strategy. Indeed, some studies have shown that participants accept more unfair offers in experimentally induced low status (Blue et al., 2016; Hu et al., 2016). Nevertheless, in these investigations behaving submissively yielded a direct economic benefit. What could explain the results of the present study, in which there was no money at stake? One possibility is that subjects were more willing to incur the risk of behaving aggressively when their status was low, as the prospect of losing increases risk-seeking (Tversky and Kahneman, 1981; Ruggeri et al., 2020). Conversely, being in a high-status position induces risk aversion so that subjects might avoid punishing lower-status individuals due to e.g. reputational concerns (Dreber et al., 2008). Put otherwise, subjects had less to lose in a low-status position, which facilitates risk-taking. In addition, inducing a low-status mindset threatens self-worth and increases hostility (Davis and Reyna, 2015), which might have further exacerbated status-dependent aggression in the present study. Future studies should disambiguate these putative mechanisms underlying status-based aggression.

\section{Changes in testosterone and cortisol concentrations}

We also observed a post-task increase in testosterone concentrations. This surge occurred instead of the decline that could be 
expected due to the hormone's circadian rhythm (Keevil et al., 2013; Buades-Rotger et al., 2016b). In men, testosterone tends to rise after winning (Geniole et al., 2017) and when achieving a higher status in skill-based hierarchies (Cheng et al., 2018). Although subjects in the present study only won half of the trials on average, they did clearly defeat one opponent and overestimated the percentage of trials won against both rivals. Indeed, elevations in testosterone levels have been linked to more positive self-appraisals of competitive performance (Casto et al., 2017). However, our data do not allow us to determine whether the changes we observed here were purely driven by competition itself, the resulting outcomes or other factors. Cortisol concentrations, on the other hand, showed a steep decline after the task. This effect, which we have previously observed (Buades-Rotger et al., 2016b), is likely due to anticipatory arousal, circadian decline and/or relaxation in the scanner; the latter might have been heightened by the post-task resting-state measurement. Nonetheless, contrary to prior studies (Carré and Olmstead, 2015), neither endogenous testosterone nor cortisol was linked with status-dependent aggressive behaviour. Our results are also in partial disagreement with the finding that competition-related surges in testosterone facilitate further antagonistic behaviour (Mehta and Josephs, 2006; Carré et al., 2013), although in the present study aggression was measured during competition rather than after it. Many experimental studies on the topic subject participants to rigged competitions in which they are clear winners or losers (Geniole et al., 2017). In contrast, the task employed here entailed a sequence of wins and losses, which might have had mutually cancelling effects on testosterone dynamics and subsequent aggressive impulses. Furthermore, testosterone increases are stronger when measured more than $10 \mathrm{~min}$ before competition (Geniole et al., 2017). Our design might have hence missed out on the preparatory testosterone rush posited to foster competitive aggression in men (Zilioli and Bird, 2017; Geniole and Carré, 2018). Recent meta-analytic evidence suggests that the association between testosterone and aggression in humans is small (Geniole et al., 2020). Testosterone-by-cortisol interactions yield even lower effect sizes across studies, with highly variable estimates and some evidence for publication bias (Dekkers et al., 2019). Large, pre-registered investigations (Brannon et al., 2019) are necessary to reach conclusive evidence on the role of testosterone in status-based aggression.

\section{Neural representations of competitive status during punishment selection}

At the neural level, we identified a number of brain regions implicated in the processing of competitive hierarchies and characterized their relevance for status-dependent aggressive behaviour. MVPA revealed that the right anterior hippocampus distinguished between the better and worse rivals during punishment selection. A growing number of studies indicate that the role of the human anterior hippocampus is not limited to mapping events in time or items in space. Rather, this structure has been suggested to encode abstract relationships between entities along several dimensions extracted from statistical regularities in the environment, i.e. relational knowledge (Garvert et al., 2017; Park et al., 2020). Similar mechanisms have been documented in the social domain so that the anterior hippocampus tracks changes in an individual's power and affiliation relative to oneself (Tavares et al., 2015; Kumaran et al., 2016). Our results therefore provide converging evidence that this region, analogous to the ventral hippocampus in rodents (Fanselow and Dong, 2010), encodes status relationships and can thereby inform social decision-making.

The left ventral and dorsal striatum also displayed multivariate signals distinguishing the high- and low-status rivals. Furthermore, participants with a stronger differentiation between opponents in the striatum showed more status-dependent aggression. Paralleling our findings, striatum neurons in the rhesus macaque brain respond differentially to social cues from dominant and submissive monkeys, which concur with a preference to watch faces from higher status individuals (Klein and Platt, 2013). The present results thus indicate that the striatum is not only sensitive to status signals (Zink et al., 2008; Zerubavel et al., 2015) and competitive outcomes (Qu et al., 2017) but also differentiates between individuals differing in status during decisions to aggress. Our findings are in line with the hypothesized role of the striatum in retaliatory aggression (Chester, 2017; Bertsch et al., 2020) and concur with meta-analytic findings demonstrating increased striatal activity when individuals deliver harsher punishments to unfair co-players (Gabay et al., 2014). Therefore, our data bridge animal and human research in showing that the hippocampus and striatum are involved in the relational processing of social dominance signals. The present findings additionally suggest that these mechanisms are at play during competitive interactions and might contribute to the adoption of aggressive strategies.

\section{Trial-wise covariation between brain activity and status-dependent aggression}

The vmPFC evinced a status-dependent covariation with participants' momentary changes in aggressive behaviour. Put another way, this region integrated status information in decisions to aggress on a trial-by-trial level. A number of volumetric and functional studies indicate that the vmPFC is crucial for the control of aggressive impulses (Beyer et al., 2015; Gilam et al., 2015; Chester et al., 2017), presumably by downregulating amygdala activity (Coccaro et al., 2011; Motzkin et al., 2015). There are however contradictory findings showing that vmPFC damage is linked with increased cooperative behaviour (Wills et al., 2018) or that vmPFC activation positively predicts aggressive decisions (Buades-Rotger et al., 2017; Repple et al., 2017). Here, the status-contingent, aggression-related elevations in vmPFC activity went along with those of other regions putatively involved in emotion regulation and social decision-making such as the dorsolateral or ventrolateral prefrontal cortex (Morawetz et al., 2015; Hackel et al., 2020). In contrast, there were no positive associations between brain structures assumed to generate aggressive urges (e.g. amygdala and periaqueductal grey) (Coccaro et al., 2011; Yu et al., 2014) and punishment selections in the task. Therefore, we speculate that the observed prefrontal and parietal activity might correspond to deliberate, intentional aggressive decisions. This assumption is supported by the finding that lost trials led to subsequently faster decisions but did not influence punishment selections, which were strongly driven by competitive status. The relatively long and invariant response times during punishment selection (i.e. around $1300 \mathrm{~ms}$ throughout the task) are also in consonance with this interpretation. Indeed, there is evidence that willingness to influence the rival's performance accounts for some variation in average punishment selections in this task (Chester and Lasko, 2019). Nonetheless, as we did not measure participants' motives, we cannot determine to which extent the intent behind louder sound blasts was mostly hostile or instrumental in nature. 


\section{Status-dependent reactivity to competitive outcomes}

Finally, there was enhanced activation for status-incongruent outcomes in the VS, AI, dACC, dorsolateral prefrontal cortex, TPJ and precuneus. More specifically, these regions showed a stronger differentiation between victories and defeats when participants were in a low- relative to a high-status position. Our results resemble those from a previous study in which subjects competed against rivals varying in status (Zink et al., 2008) and further implicate the VS in competitive hierarchy learning (Ligneul et al., 2016). The present findings are also consistent with the observation that brain areas involved in valuation (e.g. VS) and social cognition (e.g. TPJ, precuneus) display differential sensitivity to a person's position in a hierarchy (Zerubavel et al., 2015). In addition, dACC reactivity to victories in a low as compared to a high rank predicted greater aggression in the former relative to the latter. That is, the dACC response to status-enhancing wins, as compared to status-asserting ones, was correlated with greater status-dependent aggression. The local maximum observed here was located in the most posterior aspect of the dACC and lied in the near vicinity (i.e. within $5 \mathrm{~mm}$ in the sagittal and axial planes) of a meta-analytic peak for vicarious pain (Lamm et al., 2011). Concordantly, dACC activity has been linked with retaliatory behaviour (Krämer et al., 2007; Gabay et al., 2014; Beyer et al., 2015). In rodents, this brain region was reported to encode competitive effort, i.e. the net value of a reward when competition is required to attain it (Hillman and Bilkey, 2012). It is nonetheless puzzling that the dACC failed to show a clear status distinction in the decision phase. This insinuates that, in the context of competitive aggression, the dACC is more responsive to changes in status than to status cues per se. In consonance with this observation, the cingulate gyrus has been postulated to track moment-to-moment fluctuations in others' motivation during social interactions (Apps et al., 2016) as well as in their rank and power within a hierarchy (Kumaran et al., 2016). Taken together, these results tentatively suggest that status-based aggression might be particularly pronounced in persons for whom status-enhancing victories are more salient.

\section{Limitations}

There are at least three key limitations to our experimental studies. First, both samples were small and restricted to healthy young men from whom we did not collect ethnicity data. The generalizability of our findings is thus modest. Second, as commented above, we did not address participants' strategies or intent in the task. Although reaction time and neuroimaging results may provide some indirect evidence in this regard, we cannot ultimately ascertain whether subjects' punishment selections were predominantly driven by spiteful or instrumental motives, or whether they were influenced by frustration, threatened self-esteem or other affective processes. Third, participants did not face a same-status rival, which would have constituted an ideal control condition and allowed to answer additional research questions. It should be noted that confederates (five male students aged 20-30 years) were not the same in all measurements, but this is unlikely to be a major source of variability because participants did not know the identity of the other players during the game.

The correlational sports data are limited in its correlational nature and in that we did not separately consider direct encounters between low- and high-status teams. Single-match metrics that model the distance in rank between opposing teams would more closely parallel the behavioural and neuroimaging studies. Finally, sports data only included men for consistency with the experimental studies, and this also curtails the extrapolation of the obtained results to other competitions.

\section{Conclusions}

In sum, we found that low competitive status consistently evokes aggression in healthy young men. Our findings refute the notion that successful competitors are the more aggressive ones. Rather, our results indicate that those in the lower echelons of competitive hierarchies use aggression more frequently and intensely over the course of successive encounters. Our experimental data show that this holds even for situations in which aggression does not directly serve any instrumental function. Although endogenous testosterone levels increased after a competitive interaction, there were no links between this hormone and aggression, neither alone nor in interaction with cortisol. The latter finding questions a strong impact of testosterone on status-driven aggression, in line with recent meta-analytic evidence (Dekkers et al., 2019; Geniole et al., 2019). On a neural level, both anterior hippocampus and striatum displayed multivariate representations of competitive status. Interindividual differences in status-dependent aggressive behaviour could be predicted by a stronger differentiation between opponents in the striatum and by neural reactivity to status-enhancing victories in the dACC. On a trial-by-trial, within-subject basis, the vmPFC together with other prefrontal and parietal regions favoured status-based aggression. Our study thus reveals a consistent association between low competitive status and aggression and points towards potential neural mechanisms underlying this relationship.

\section{Funding}

This study was funded by the German Science Foundation (grant number KR3691/5-1). We are grateful to Susanne Schellbach and Mourad Zoubir for their help with the data acquisition and to our subjects and confederates for their participation.

\section{Conflicts of interest}

The authors report no conflicts of interest.

\section{Supplementary data}

Supplementary data are available at SCAN online.

\section{References}

Apps, M.A.J., Rushworth, M.F.S., Chang, S.W.C. (2016). The anterior cingulate gyrus and social cognition: tracking the motivation of others. Neuron, 90, 692-707.

Barr, D.J., Levy, R., Scheepers, C., et al. (2013). Random effects structure for confirmatory hypothesis testing: keep it maximal. Journal of Memory and Language, 68, 255-78.

Berkowitz, L. (2012). A different view of anger: the cognitiveneoassociation conception of the relation of anger to aggression. Aggressive Behavior, 38, 322-33.

Berri, D.J., Rodenberg, R.M. (2012). Crime and punishment in the National Basketball Association. In: Jewell, R.T., editor. Violence 
and Aggression in Sporting Contests: Economics, History and Policy, New York, NY: Springer, 65-76.

Bertsch, K., Florange, J., Herpertz, S.C. (2020). Understanding brain mechanisms of reactive aggression. Current Psychiatry Reports, 22, 81.

Beyer, F., Münte, T.F., Göttlich, M., et al. (2015). Orbitofrontal cortex reactivity to angry facial expression in a social interaction correlates with aggressive behavior. Cerebral Cortex, 25, 3057-63.

Blue, P.R., Hu, J., Wang, X., et al. (2016). When do low status individuals accept less? The interaction between self- and otherstatus during resource distribution. Frontiers in Psychology, 7, 1667.

Brannon, S.M., Carr, S., Jin, E.S., et al. (2019). Exogenous testosterone increases sensitivity to moral norms in moral dilemma judgements. Nature Human Behaviour, 3, 856-66.

Buades-Rotger, M., Brunnlieb, C., Münte, T.F., et al. (2016a). Winning is not enough: ventral striatum connectivity during physical aggression. Brain Imaging and Behavior, 10, 105-14.

Buades-Rotger, M., Engelke, C., Beyer, F., et al. (2016b). Endogenous testosterone is associated with lower amygdala reactivity to angry faces and reduced aggressive behavior in healthy young women. Scientific Reports, 6, 38538.

Buades-Rotger, M., Beyer, F., Krämer, U.M. (2017). Avoidant responses to interpersonal provocation are associated with increased amygdala and decreased mentalizing network activity. eNeuro, 4.

Buades-Rotger, M., Engelke, C., Krämer, U.M. (2019). Trait and state patterns of basolateral amygdala connectivity at rest are related to endogenous testosterone and aggression in healthy young women. Brain Imaging and Behavior, 13, 564-76.

Buades-Rotger, M., Krämer, U.M. (2018). From words to action: implicit attention to antisocial semantic cues predicts aggression and amygdala reactivity to angry faces in healthy young women. Aggressive Behavior, 44, 624-37.

Carré, J.M., Campbell, J.A., Lozoya, E., et al. (2013). Changes in testosterone mediate the effect of winning on subsequent aggressive behaviour. Psychoneuroendocrinology, 38, 2034-41.

Carré, J.M., Olmstead, N.A. (2015). Social neuroendocrinology of human aggression: examining the role of competitioninduced testosterone dynamics. Neuroscience, 286, 171-86.

Casto, K.V., Rivell, A., Edwards, D.A. (2017). Competition-related testosterone, cortisol, and perceived personal success in recreational women athletes. Hormones and Behavior, 92, 29-36.

Casto, K.V., Edwards, D.A. (2016). Testosterone, cortisol, and human competition. Hormones and Behavior, 82, 21-37.

Cheng, J.T., Kornienko, O., Granger, D.A. (2018). Prestige in a large-scale social group predicts longitudinal changes in testosterone. Journal of Personality and Social Psychology, 114, 924-44.

Cheng, J.T. (2020). Dominance, prestige, and the role of leveling in human social hierarchy and equality. Current Opinion in Psychology, 33, 238-44.

Chester, D.S. (2017). The role of positive affect in aggression. Current Directions in Psychological Science, 26, 366-70.

Chester, D.S., Lynam, D.R., Milich, R., et al. (2017). Physical aggressiveness and gray matter deficits in ventromedial prefrontal cortex. Cortex, 97, 17-22.

Chester, D.S., DeWall, C.N. (2016). The pleasure of revenge: retaliatory aggression arises from a neural imbalance toward reward. Social Cognitive and Affective Neuroscience, 11, 1173-82.
Chester, D.S., Lasko, E.N. (2019). Validating a standardized approach to the Taylor aggression paradigm. Social Psychological and Personality Science, 10, 620-31.

Chow, G.M., Murray, K.E., Feltz, D.L. (2009). Individual, team, and coach predictors of players' likelihood to aggress in youth soccer. Journal of Sport and Exercise Psychology, 31, 425.

Coates, D., Battré, M., Deutscher, C. (2012). Does violence in professional ice hockey pay? Cross country evidence from three leagues. In: Jewell, R.T., editor. Violence and Aggression in Sporting Contests: Economics, History and Policy, New York, NY: Springer, 47-63.

Coccaro, E.F., Sripada, C.S., Yanowitch, R.N., et al. (2011). Corticolimbic function in impulsive aggressive behavior. Biological Psychiatry, 69, 1153-9.

Coulomb-Cabagno, G., Rascle, O. (2006). Team sports players' observed aggression as a function of gender, competitive level, and sport type. Journal of Applied Social Psychology, 36, 1980-2000.

Da Cunha-bang, S., Fisher, P.M., Hjordt, L.V., et al. (2017). Violent offenders respond to provocations with high amygdala and striatal reactivity. Social Cognitive and Affective Neuroscience, 12, 802-10.

Davis, J.R., Reyna, C. (2015). Seeing red: how perceptions of social status and worth influence hostile attributions and endorsement of aggression. British Journal of Social Psychology, $54,728-47$.

Dekkers, T.J., van Rentergem, J.A.A., Meijer, B., et al. (2019). A meta-analytical evaluation of the dual-hormone hypothesis: does cortisol moderate the relationship between testosterone and status, dominance, risk taking, aggression, and psychopathy? Neuroscience and Biobehavioral Reviews, 96, 250-71.

Dowsett, A., Jackson, M. (2019). The effect of violence and competition within video games on aggression. Computers in Human Behavior, 99, 22-7.

Dreber, A., Rand, D.G., Fudenberg, D., et al. (2008). Winners don't punish. Nature, 452, 348-51.

Dreher, J.-C., Dunne, S., Pazderska, A., et al. (2016). Testosterone causes both prosocial and antisocial status-enhancing behaviors in human males. Proceedings of the National Academy of Sciences of the United States of America, 113, 11633-8.

Eisenegger, C., Haushofer, J., Fehr, E. (2011). The role of testosterone in social interaction. Trends in Cognitive Sciences, 15, 263-71.

Fanselow, M.S., Dong, H.-W. (2010). Are the dorsal and ventral hippocampus functionally distinct structures? Neuron, 65, 7-19.

Gabay, A.S., Radua, J., Kempton, M.J., et al. (2014). The ultimatum game and the brain: a meta-analysis of neuroimaging studies. Neuroscience and Biobehavioral Reviews, 47, 549-58.

Garvert, M.M., Dolan, R.J., Behrens, T.E.J. (2017). A map of abstract relational knowledge in the human hippocampal-entorhinal cortex. eLife, 6, e17086.

Geniole, S.N., Bird, B.M., Ruddick, E.L., et al. (2017). Effects of competition outcome on testosterone concentrations in humans: an updated meta-analysis. Hormones and Behavior, 92, 37-50.

Geniole, S.N., Bird, B.M., McVittie, J.S., et al. (2019). Is testosterone linked to human aggression? A meta-analytic examination of the relationship between baseline, dynamic, and manipulated testosterone on human aggression. Hormones and Behavior, 123, 104644.

Geniole, S.N., Bird, B.M., McVittie, J.S., et al. (2020). Is testosterone linked to human aggression? A meta-analytic examination of the relationship between baseline, dynamic, and manipulated 
testosterone on human aggression. Hormones and Behavior, 123, 104644.

Geniole, S.N., Carré, J.M. (2018). Human social neuroendocrinology: review of the rapid effects of testosterone. Hormones and Behavior, 104, 192-205.

Gilam, G., Lin, T., Raz, G., et al. (2015). Neural substrates underlying the tendency to accept anger-infused ultimatum offers during dynamic social interactions. Neurolmage, 120, 400-11.

Hackel, L.M., Wills, J.A., Van Bavel, J.J. (2020). Shifting prosocial intuitions: neurocognitive evidence for a value-based account of group-based cooperation. Social Cognitive and Affective Neuroscience, 15, 371-81.

Han, C., Watkins, C.D., Nan, Y., et al. (2021). Exogenous testosterone decreases men's sensitivity to vocal cues of male dominance. Hormones and Behavior, 127, 104871.

Hassabis, D., Spreng, R.N., Rusu, A.A., et al. (2013). Imagine all the people: how the brain creates and uses personality models to predict behavior. Cerebral Cortex, 24, 1979-87.

Hauge, J.A. (2012). Incentive for aggression in American football. In: Jewell, R.T., editor. Violence and Aggression in Sporting Contests: Economics, History and Policy, New York, NY: Springer, 29-46.

Hebart, M.N., Görgen, K., Haynes, J.-D. (2015). The Decoding Toolbox (TDT): a versatile software package for multivariate analyses of functional imaging data. Frontiers in Neuroinformatics, 8 , 88.

Hillman, K.L., Bilkey, D.K. (2012). Neural encoding of competitive effort in the anterior cingulate cortex. Nature Neuroscience, 15, 1290-7.

Horton, R.S., Sedikides, C. (2009). Narcissistic responding to ego threat: when the status of the evaluator matters. Journal of Personality, 77, 1493-525.

Hu, J., Blue, P.R., Yu, H., et al. (2016). Social status modulates the neural response to unfairness. Social Cognitive and Affective Neuroscience, 11, 1-10.

Inoue, Y., Takahashi, T., Burriss, R.P., et al. (2017). Testosterone promotes either dominance or submissiveness in the ultimatum game depending on players' social rank. Scientific Reports, 7, 5335.

Jewell, R.T. (2012). Aggressive play and demand for English Premier League football. In: Jewell, R.T., editor. Violence and Aggression in Sporting Contests: Economics, History and Policy, New York, NY: Springer, 113-31.

Josephs, R.A., Sellers, J.G., Newman, M.L., et al. (2006). The mismatch effect: when testosterone and status are at odds. Journal of Personality and Social Psychology, 90, 999-1013.

Kakkar, H., Sivanathan, N., Gobel, M.S. (2019). Fall from grace: the role of dominance and prestige in the punishment of highstatus actors. Academy of Management Journal, 63, 530-53.

Kakkar, H., Sivanathan, N. (2017). When the appeal of a dominant leader is greater than a prestige leader. Proceedings of the National Academy of Sciences of the United States of America, 114, 6734-9.

Keevil, B., MacDonald, P., Macdowall, W., et al. (2013). Salivary testosterone measurement by liquid chromatography tandem mass spectrometry in adult males and females. Annals of Clinical Biochemistry, 51, 368-78.

King, A.R., Russell, T.D. (2019). Lifetime Acts of Violence Assessment (LAVA) predictors of laboratory aggression. Aggressive Behavior, 45, 477-88.

Kirker, B., Tenenbaum, G., Mattson, J. (2000). An investigation of the dynamics of aggression: direct observations in ice hockey and basketball. Research Quarterly for Exercise and Sport, 71, 373-86.
Klein, J.T., Platt, M.L. (2013). Social information signaling by neurons in primate striatum. Current Biology: CB, 23, 691-6.

Krämer, U.M., Jansma, H., Tempelmann, C., et al. (2007). Tit-fortat: the neural basis of reactive aggression. NeuroImage, 38, 203-11.

Kumaran, D., Melo, H.L., Duzel, E. (2012). The emergence and representation of knowledge about social and nonsocial hierarchies. Neuron, 76, 653-66.

Kumaran, D., Banino, A., Blundell, C., et al. (2016). Computations underlying social hierarchy learning: distinct neural mechanisms for updating and representing self-relevant information. Neuron, 92, 1135-47.

Kuznetsova, A., Brockhoff, P.B., Christensen, R.H.B. (2017). lmerTest package: tests in linear mixed effects models. Journal of Statistical Software, 82, 1-26.

Lakens, D. (2013). Calculating and reporting effect sizes to facilitate cumulative science: a practical primer for t-tests and ANOVAs. Frontiers in Psychology, 4, 863.

Lamm, C., Decety, J., Singer, T. (2011). Meta-analytic evidence for common and distinct neural networks associated with directly experienced pain and empathy for pain. NeuroImage, 54, 2492-502.

Laustsen, L., Petersen, M.B. (2017). Perceived conflict and leader dominance: individual and contextual factors behind preferences for dominant leaders. Political Psychology, 38, 1083-101.

Lee, H.Y., Yeager, D.S. (2020). Adolescents with an entity theory of personality are more vigilant to social status and use relational aggression to maintain social status. Social Development, 29, 273-89.

Ligneul, R., Obeso, I., Ruff, C.C., et al. (2016). Dynamical representation of dominance relationships in the human rostromedial prefrontal cortex. Current Biology, 26, 3107-15.

Losecaat-Vermeer, A., Boksem, M., Gausterer, C., et al. (2020). Testosterone increases risk-taking for status but not for money. PsyArXiv.

Maldjian, J.A., Laurienti, P.J., Kraft, R.A. et al. (2003). An automated method for neuroanatomic and cytoarchitectonic atlas-based interrogation of fMRI data sets. NeuroImage, 19, 1233-9.

Mehta, P.H., Josephs, R.A. (2006). Testosterone change after losing predicts the decision to compete again. Hormones and Behavior, 50, 684-92.

Morawetz, C., Bode, S., Baudewig, J., et al. (2015). Changes in effective connectivity between dorsal and ventral prefrontal regions moderate emotion regulation. Cerebral Cortex, 26, 1923-37.

Motzkin, J.C., Philippi, C.L., Wolf, R.C., et al. (2015). Ventromedial prefrontal cortex is critical for the regulation of amygdala activity in humans. Biological Psychiatry, 77, 276-84.

Muller, D., Bushman, B.J., Subra, B., et al. (2012). Are people more aggressive when they are worse off or better off than others? Social Psychological and Personality Science, 3, 754-9.

Muscatell, K.A., Morelli, S.A., Falk, E.B., et al. (2012). Social status modulates neural activity in the mentalizing network. NeuroImage, 60, 1771-7.

Næss, F.D. (2001). Narratives about young men and masculinities in organised sport in Norway. Sport, Education and Society, 6, $125-42$.

Oxford, J.K., Tiedtke, J.M., Ossmann, A., et al. (2017). Endocrine and aggressive responses to competition are moderated by contest outcome, gender, individual versus team competition, and implicit motives. PLoS One, 12, e0181610. 
Pappas, N.T., McKenry, P.C., Catlett, B.S. (2004). Athlete aggression on the rink and off the ice: athlete violence and aggression in hockey and interpersonal relationships. Men and Masculinities, 6, 291-312.

Park, S.A., Miller, D.S., Nili, H., et al. (2020). Map making: constructing, combining, and inferring on abstract cognitive maps. Neuron, 107, 1226-1238.e8.

Perogamvros, I., Owen, L.J., Newell-Price, J., et al. (2009). Simultaneous measurement of cortisol and cortisone in human saliva using liquid chromatography-tandem mass spectrometry: application in basal and stimulated conditions. Journal of Chromatography B, 877, 3771-5.

Przybylski, A.K., Deci, E.L., Rigby, C.S., et al. (2014). Competenceimpeding electronic games and players' aggressive feelings, thoughts, and behaviors. Journal of Personality and Social Psychology, 106, 441-57.

Qu, C., Ligneul, R., Van der Henst, J.-B., et al. (2017). An integrative interdisciplinary perspective on social dominance hierarchies. Trends in Cognitive Sciences, 21, 893-908.

Repple, J., Pawliczek, C.M., Voss, B., et al. (2017). From provocation to aggression: the neural network. BMC Neuroscience, 18, 73.

Revelle, W. (2017). Psych: Procedures for Personality and Psychological Research, Evanston, IL: Northwestern University.

Ruggeri, K., Alí, S., Berge, M.L., et al. (2020). Replicating patterns of prospect theory for decision under risk. Nature Human Behaviour, 4, 622-33.

Saalfeld, V., Ramadan, Z., Bell, V., et al. (2018). Experimentally induced social threat increases paranoid thinking. Royal Society Open Science, 5, 180569.

Sapolsky, R.M. (2004). Social status and health in humans and other animals. Annual Review of Anthropology, 33, 393-418.

Sapolsky, R.M. (2005). The influence of social hierarchy on primate health. Science, 308, 648-52.

Schafer, M., Schiller, D. (2018). Navigating social space. Neuron, 100, 476-89.

Tavares, R.M., Mendelsohn, A., Grossman, Y., et al. (2015). A map for social navigation in the human brain. Neuron, 87, 231-43.

Terburg, D., van Honk, J. (2013). Approach-avoidance versus dominance-submissiveness: a multilevel neural framework on how testosterone promotes social status. Emotion Review, 5, 296-302.

Trebicky, V., Havlícek, J., Roberts, S.C., et al. (2013). Perceived aggressiveness predicts fighting performance in mixedmartial-arts fighters. Psychological Science, 24, 1664-72.
Tversky, A., Kahneman, D. (1981). The framing of decisions and the psychology of choice. Science, 211, 453-8.

Votinov, M., Pripfl, J., Windischberger, C., et al. (2015). Better you lose than I do: neural networks involved in winning and losing in a real time strictly competitive game. Scientific Reports, 5, 11017.

Waasdorp, T.E., Baker, C.N., Paskewich, B.S., et al. (2013). The association between forms of aggression, leadership, and social status among urban youth. Journal of Youth and Adolescence, 42, 263-74.

Waddell, J.C., Peng, W. (2014). Does it matter with whom you slay? The effects of competition, cooperation and relationship type among video game players. Computers in Human Behavior, $38,331-8$.

Wagels, L., Votinov, M., Kellermann, T., et al. (2018). Exogenous testosterone enhances the reactivity to social provocation in males. Frontiers in Behavioral Neuroscience, 12, 37.

Weick, M. (2020). Power and aggression: making sense of a fickle relationship. Current Opinion in Psychology, 33, 245-9.

Wickham, H. (2016). Ggplot2: Elegant Graphics for Data Analysis, 2nd ed, New York: Springer.

Wills, J., FeldmanHall, O., NYU PROSPEC Collaboration, et al. (2018). Dissociable contributions of the prefrontal cortex in group-based cooperation. Social Cognitive and Affective Neuroscience, 13, 349-56.

Wu, Y., Zhang, Y., Ou, J., et al. (2020). Exogenous testosterone increases the audience effect in healthy males: evidence for the social status hypothesis. Proceedings of the Royal Society B: Biological Sciences, 287, 20200976.

Yu, R., Mobbs, D., Seymour, B., et al. (2014). The neural signature of escalating frustration in humans. Cortex, 54, 165-78.

Zerubavel, N., Bearman, P.S., Weber, J., et al. (2015). Neural mechanisms tracking popularity in real-world social networks. Proceedings of the National Academy of Sciences of the United States of America, 112, 15072.

Zilioli, S., Bird, B.M. (2017). Functional significance of men's testosterone reactivity to social stimuli. Frontiers in Neuroendocrinology, 47, 1-18.

Zink, C.F., Tong, Y., Chen, Q., et al. (2008). Know your place: neural processing of social hierarchy in humans. Neuron, 58, 273-83. 